\title{
Educar ou instruir? Narrativas anarcossindicalistas nos primeiros anos da República Portuguesa: Revista Lumen (Lisboa, 1911-1913) ${ }^{1}$
}

\author{
Educate or instruct? Anarcho-syndicalist narratives in the early years of the Portuguese \\ Republic: Lumen magazine (Lisbon, 1911-1913)
}

¿Educar o instruir? Narrativas anarcosindicalistas en los primeros años de la República Portuguesa: revista Lumen (Lisboa, 1911-1913)

\section{LUIZ CARLOS BARREIRA ${ }^{2}$}

\section{Resumo}

Este artigo focaliza as ações de um grupo de intelectuais portugueses no início do século XX que se apresentava como anarcossindicalista. Autodenominado Grupo Lumen, suas ações visavam à formação do ser social. Dentre tais ações, o texto destaca a criação de uma revista, intitulada Lumen, por meio da qual o Grupo publicou suas teses sobre o educar e o instruir, tendo como referência as experiências da Escola Oficina $\mathrm{N}^{\circ} 1$ de Lisboa e da Escola Moderna de Ferrer y Guardia, em Barcelona. A perspectiva de análise adotada pelo autor situa a imprensa no terreno da história social, no âmbito do qual ela é concebida como um conjunto de práticas constitutivas do social. Por meio da imprensa, o Grupo Lumen propôs um programa de instrução laica, científica e livre como condição necessária à criação de uma sociedade ácrata.

Palavras-chave: Anarcossindicalismo, Formação libertária, Revista Lumen. Portugal.

\footnotetext{
${ }^{1}$ Este artigo traz resultados de pesquisa histórica sobre a imprensa portuguesa de educação e ensino voltada para a formação do trabalhador urbano, no início do Século XX. Tal pesquisa, configurada no projeto Imprensa Periódica e Circulação de Modelos Sociopedagógicos: Experiências de Educação Libertária em Portugal no Limiar do Regime Republicano (1911-1919), contou com o apoio financeiro da Fundação de Amparo à Pesquisa do Estado de São Paulo.

${ }^{2}$ Doutor em Educação (Filosofia e História da Educação) pela Universidade Estadual de Campinas, com estágio pós-doutoral realizado na Universidade de Lisboa. Professor no Programa de Pós-Graduação em Educação da Universidade Católica de Santos. E-mail: luizcarlosbarreira@gmail.com.
} 


\begin{abstract}
This article focuses on the actions of a group of Portuguese intellectuals in the early twentieth century who presented itself as anarcho-syndicalist. Calling itself Lumen Group, its actions aimed at the formation of the human being. Among such actions, the text highlights the creation of a magazine, entitled Lumen, through which the Group published its thesis on educating and instructing, choosing as a reference the experiences of the Escola Oficina $N^{o} 1$ of Lisbon and the Escola Moderna, directed by Ferrer y Guardia, in Barcelona. The analytical perspective adopted by the author puts the press in the field of social history, under which it is conceived as a set of constitutive social practices. Through the press, the Lumen Group proposed a secular, scientific and free education program as a necessary component to create a selfgoverned (stateless) society.
\end{abstract}

Keywords: Anarcho-syndicalism, Libertarian formation, Lumen Magazine. Portugal.

\title{
Resumen
}

Este artículo se centra en las acciones de un grupo de intelectuales portugueses a principios del siglo XX que se presentaba como anarcosindicalista. Autodenominado Grupo Lumen, sus acciones apunta a la formación del ser social. Entre estas acciones, el texto destaca la creación de una revista, titulada Lumen, por medio de la cual el Grupo publicó sus tesis sobre el educar y el instruir, eligiendo como referencia las experiencias de la Escuela Oficina $N^{o} 1$ de Lisboa y de la Escuela Moderna de Ferrer y Guardia, en Barcelona. La perspectiva de análisis adoptada por el autor sitúa a la prensa en el terreno de la historia social, en el marco del cual ella es concebida como un conjunto de prácticas constitutivas de lo social. A través de la prensa, el Grupo Lumen propuso un programa de instrucción laica, científica y libre como condición necesaria a la construcción de una sociedad ácrata.

Palabras clave: Anarcosindicalismo; Formación libertaria, Revista Lumen. Portugal. 
A princípio o laicismo satisfazia suficientemente as aspirações populares. Quando, porém, se foi compreendendo que nas escolas laicas não se fazia outra coisa que pôr o civismo no lugar da religião, o Estado no lugar de Deus, surgiu a ideia de um ensino alheio às doutrinas tanto religiosas como políticas. Então foi proclamada por uns a escola neutral, por outros a racionalista (Acción Libertária ${ }^{3}$ ).

Lumen - A Vida e o Ideal. Esse é o título de uma revista pertencente a um grupo de intelectuais portugueses, denominado Grupo Lumen. Os integrantes desse grupo se apresentavam como anarquistas e sindicalistas revolucionários e elegeram a imprensa como uma de suas principais trincheiras na luta contra o status quo, em prol da construção de uma sociedade ácrata ${ }^{4}$. Editada mensalmente na cidade de Lisboa, o primeiro número de Lumen veio a público em maio de 1911. A partir de então, e até setembro de 1913, deixou de circular apenas uma ou duas vezes ${ }^{5}$.

\section{Figura 1 - Capa da revista Lumen}

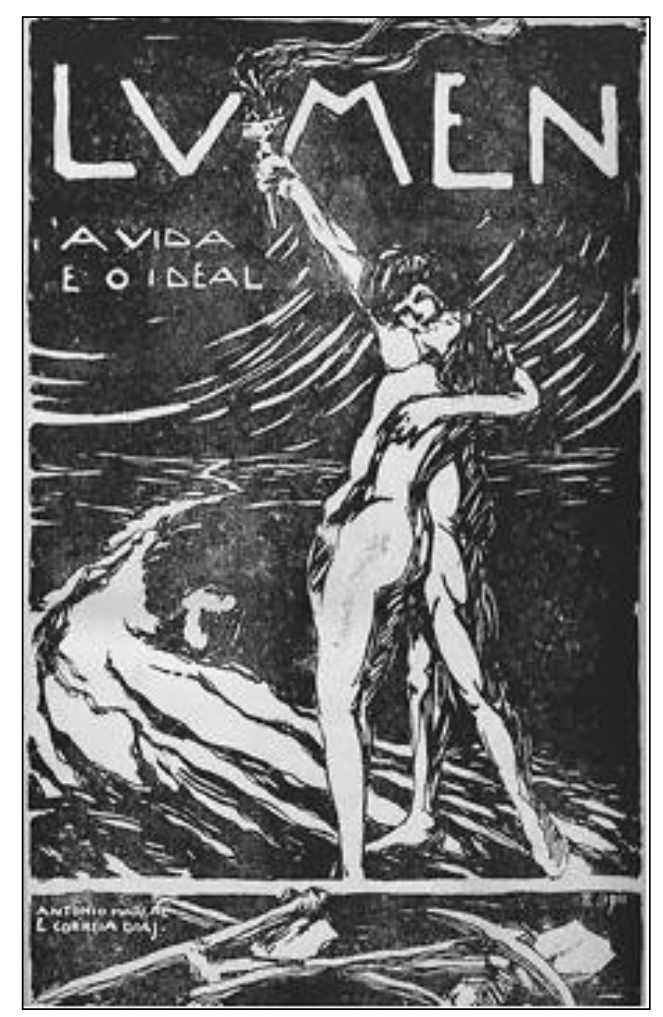

Fonte: Hemeroteca da Biblioteca Pública Municipal do Porto.

\footnotetext{
${ }^{3}$ Acción Libertária, “O Problema do Ensino", Lumen, Lisboa, vol. II, no 15, p. 57, dez. 1912. Exceção feita aos títulos e demais nomes próprios, optei por atualizar a ortografia observada nas fontes originais, conforme o Acordo Ortográfico de 2008.

${ }^{4}$ Neste trabalho, a imprensa é abordada com base em pressupostos e procedimentos firmados pela história social, com destaque para aqueles que a tomam como "uma força ativa na história" (DARNTON, 1996, p. 15), "articulando a análise de qualquer publicação ou periódico ao campo de lutas sociais no interior do qual se constitui e atua" (CRUZ e PEIXOTO, 2007, p. 257). De acordo com essa perspectiva de análise, os estudos sobre impressos (anais, boletins, revistas e jornais, dentre outros) não se restringem, portanto, aos artefatos propriamente ditos. Nesses termos, um dos principais objetivos de investigações sobre imprensa é a identificação dos sujeitos que a concebem como estratégia de luta, suas alianças e disputas, assim como a análise dos seus projetos de reconstrução do social.

${ }^{5}$ Tal dedução resulta da análise que o autor fez do periódico em questão, cuja coleção - informada como "completa" - foi localizada na hemeroteca da Biblioteca Pública Municipal da Cidade do Porto.
} 
A Redação de Lumen foi inicialmente instalada na Rua Áurea, $n^{\circ} 74,4^{\circ}$ piso, mas logo em seguida foi transferida para a Rua dos Remolares, $n^{\circ} 35,2^{\circ}$ piso. Seus três primeiros números foram compostos e impressos na Imprensa de Manuel Lucas Torres, situada na Rua do Diário de Notícias, nº 93, e, os demais, na Typographia Minerva, Famalicão. A partir do $13^{\circ}$ número, verifica-se uma pequena mas significativa mudança em parte do complemento do título da revista: a expressão "A Vida e o Ideal” permanece, mas o complemento, "Crítica, Sociologia e Arte", é substituído por outro, qual seja "Páginas Livres". Tal mudança coincide com a substituição do editor da revista. Até junho de 1912, Joaquim Madureira, também conhecido por Braz Burity, exerceu a função. A partir de então, e até setembro de 1913, Madureira foi substituído por Albano Martins. A revista teve, entretanto, um único diretor: Severino de Carvalho, também conhecido por Bel-Adam. O último número de Lumen traz um comunicado aos leitores - reproduzido parcialmente a seguir -, no qual editor e dirigente fazem referência às dificuldades - notadamente financeiras - enfrentadas pelo Grupo, e anunciam a suspensão do periódico, mas por tempo determinado.

Ninguém nos quis ouvir.

[...] Lumen, suspende, pois, a sua publicação por algum tempo. No princípio de 1914 - janeiro ou fevereiro - reaparecerá sob outro título - A Cultura Popular talvez -, com as suas seções remodeladas, mas sem perder de vista as três formas de emancipação humana, a que foi seu propósito consagra-se: a econômico-social, a intelectual e a moral. (Lumen, vol. II, nº 24, p. 292, set. 1913).

Tal previsão, entretanto, não se verificou. Muito provavelmente, a participação de Portugal na Primeira Guerra Mundial, entre outros motivos (ainda não conhecidos), deve ter frustrado tal desejo dos dirigentes do Grupo Lumen. Sabe-se que veio a público, em 1919, um boletim sob o título Cultura Popular. ${ }^{6}$ Apesar de alguns fortes indícios, não se pode afirmar, entretanto, ter sido esse periódico aquele que deveria ter dado continuidade aos trabalhos iniciados pelo Grupo Lumen.

Apesar de a revista Lumen não ser um periódico dedicado exclusivamente à educação escolar, esta não deixou de ser nela considerada, tanto por seus editores, Joaquim Madureira e Albano Martins - especialmente pelo primeiro -, como por alguns de seus mais frequentes colaboradores, a exemplo de Adolfo Lima, Emílio Costa e César Porto, entre outros.

O lugar que editores e colaboradores da revista Lumen atribuíam à educação escolar, no processo de construção de uma sociedade ácrata em Portugal, em um momento singular da história social e política daquele país - o da implantação da república -, será o primeiro tópico apresentado e problematizado neste artigo. Na sequência, duas experiências educacionais que chamaram a atenção dos editores e colaboradores de Lumen serão apresentadas e problematizadas: a paradigmática Escola Moderna, criada por Francisco Ferrer y Guardia, em 1901, e a não menos paradigmática Escola Oficina No 1 de Lisboa, criada pela Sociedade

\footnotetext{
${ }^{6}$ Propriedade da Fundação Ateneu Popular. Sediada em Lisboa, essa fundação foi criada em junho de 1917 por integrantes de um grupo de estudos - Grupo de Estudos Sociais de Alcântara - constituído somente por operários, do qual fizeram parte: Pinto Quartim, Teixeira Danton, Sebastião Eugénio, Artur Freitas e António Evaristo, entre outros. (Cf. BARREIRA, 2011, p. 340).
} 
Promotora de Asilos, Creches e Escolas, em 1905. ${ }^{7}$ A posição assumida pelo Grupo Lumen, quanto ao educar e ao instruir, encerrará a discussão do tema e do problema privilegiados neste artigo: a importância de se estar atento à historicidade do social, na análise que hoje fazemos das práticas educativas, tanto do passado quanto do tempo presente.

\section{Um Diagnóstico da Educação Escolar em Portugal no Início da República}

Associações de classe proliferaram em Portugal no primeiro quartel do século XX e quase todas fizeram-se acompanhar de "aulas de primeiras letras que funcionavam anexas a estas Associações.” (CANDEIAS, 1987, p. 327). Tais aulas (escolas) visavam à criação de

uma verdadeira rede escolar, autónoma e alternativa face à rede educativa estatal. Autónoma porque independente do Estado, alternativa porque sendo os seus fins últimos a preparação e formação de "Homens Livres" que participassem na construção da grande Utopia Anarquista, esta formação teria que assentar em pressupostos pedagógicos que rompessem com os métodos antiquados repressivos e domesticadores que [...] caracterizavam a educação do Estado. (CANDEIAS, 1987, p. 327).

Adolfo Lima, um dos principais colaboradores da revista Lumen, esclarece bem, nos vários artigos que publicou nessa revista, a importância que os libertários de então atribuíam, tanto ao ensino desinteressado e científico, quanto à educação. Em um desses artigos, intitulado "Educação Integral", critica a cultura política da escola, que no início do regime republicano queria impor mudanças às práticas escolares, assim como a cultura prático-empírica de mestres e professores, os quais não sabiam (ou não queriam) reagir a tais imposições. Temos, aqui, a voz do especialista, a cultura do especialista, a tecer considerações sobre as outras duas culturas que têm por referência a escola, consoantes os estudos de Escolano Benito (2005).

Lima (1911) inicia esse seu artigo destacando a importância do momento histórico de então, notadamente porque o problema educativo começava a receber a importância que merecia. Para respaldar essa sua opinião, informa o significativo número de livros sobre educação publicados, em 1910, nos Estados Unidos da América do Norte (348), Inglaterra (578), França (1.005) e Alemanha (4.203). Nenhum dado, entretanto, sobre Portugal (Cf. LIMA, 1911, p. 116, nota de rodapé $\left.n^{\circ} 1\right)$.

Segundo Lima (1911), revolucionários e evolucionistas haviam finalmente compreendido o que os jesuítas já haviam percebido há muitos anos: que a educação era "o meio, o processo de alcançar a civilização, o progresso, o futuro humano" (p. 116). Sem educação - completa o autor -, não poderiam ser nem revolucionários, nem evolucionistas, ou

\footnotetext{
${ }^{7}$ A Sociedade Promotora de Asilos, Creches e Escolas era uma associação de republicanos controlada pela maçonaria. Inicialmente voltada para a formação profissional de trabalhadores urbanos, a Escola Oficina teria promovido, segundo Candeias (1994), uma verdadeira revolução silenciosa no campo da educação escolar, com a inclusão de intelectuais libertários em seu quadro de professores, como os irmãos Adolfo e António Lima, Emílio Costa e Deolinda Lopes Vieira (esposa de António Pinto Quartin), entre outros. Esses professores teriam sido os principais responsáveis por uma nova forma de educar, orientada por saberes e práticas de inspiração libertária.
} 
as duas coisas ao mesmo tempo, o que seria, segundo ele, "mais cientifico". O cabedal de conhecimentos "certos e científicos", adquiridos na escola, seria condição necessária, para que o ser social alcançasse "a suprema educação do ponto de vista moral”. O que só seria possível a partir do momento que o indivíduo tomasse consciência de tal necessidade e quisesse desenvolver essa consciência em harmonia com o seu saber. Assim procedendo, teria o seu caráter formado ou, nas palavras do autor, teria alcançado "a suprema educação do ponto de vista moral" (LIMA, 1911, p. 116).

Mas como chegar à consciência de tal necessidade? A quem competiria, afinal, despertar tal consciência no indivíduo? Segundo Lima, os políticos não se importavam com a educação. Apoiando-se em Montesquieu, qualificava-os de "medíocres e mexeriqueiros", possuidores de todos os truques "da arte da velhacaria" (LIMA, 1911, p. 117). Para tais sujeitos, o problema educativo seria apenas um número de efeito nos seus pomposos programas políticos, tendo em vista conquistar as massas (ingênuos, sinceros e honestos). Seria preciso, portanto, libertar a educação da tutela política. Mas quem possibilitaria tal libertação? Eis a resposta dada por Lima:

Os pedagogos, os homens de ciência bem proclamam, bem procuram estabelecer um critério, elevado, independente, emancipador, que liberte a Educação da tutela política. As suas obras, os seus escritos são matéria mais do que suficiente para estabelecer uma orientação firme a seguir no problema da Educação, mas não são ouvidos e quando fingem que os consultam é para fazerem o contrário do que eles preconizam e em seguida afastam-nos manhosamente, seguindo processos e estratagemas jesuíticos. (LIMA, 1911, p. 118-119).

O ilustre educador português constata, assim, o divórcio entre duas dimensões da cultura escolar naquele singular momento da história de Portugal, a saber: a cultura científica (do especialista, dos pedagogos e dos homens de ciência) e a cultura política. Mas não foi apenas em relação aos políticos que os especialistas aos quais Lima de refere se sentiam divorciados. Esse mesmo sentimento também estava presente na relação que tentavam estabelecer e manter com outra dimensão da cultura escolar, qual seja, a cultura prático-empírica, a cultura do mestre artesão, como Escolano Benito (2005) a denominou. As representações de Adolfo Lima sobre mestres e professores portugueses daquele período, que a seguir reproduzimos, evidenciam tal sentimento.

Deitem-se os olhos para os corpos docentes dos estabelecimentos oficiais: o que lá vemos são politicantes em vez de professores. (...) Os professores na sua maioria pertencem ou estão envolvidos na engrenagem do caciquismo oficial, cuidando mais de votos e de intrigas do que de exercer honestamente uma profissão de tanta responsabilidade. Colocados por empenhos - como por empenhos fizeram exames, como por empenhos têm conseguido tudo na sua vida - embora sob a aparência de um concurso, não têm a paixão do ensino, da ciência - como se prova, aliás, pelo fato de não criarem ciência, senão excepcionalmente, um ou outro. Com o seu cérebro afeito unicamente aos casos concretos da alcovitice indígena, não se adaptam à especulação científica, à sua 
elevadíssima missão, que consideram uma maçada, adotando por isso nas suas aulas os livros alheios, o trabalho dos outros e não produzindo todos os anos uma obra constituída pelas suas preleções originais. (LIMA, 1911, p. 119; grifos do autor).

Os intelectuais libertários da revista Lumen, aqui representados por Adolfo Lima, não afirmam, mas deixam subentendido que esperavam que as associações de classe criassem suas próprias instituições de ensino, independentes do Estado. Apostavam na formação de professores, mas de acordo com os princípios traçados pela ciência (pela Sociologia, especialmente) e por iniciativa de instituições igualmente independentes do Estado. Nesse sentido, são expressões concretas de forças sociais contrárias a uma organização social orquestrada pelas ações de um Estado cerceador da liberdade de ser e viver.

Pesquisas historiográficas relativamente recentes, como a de Candeias (1994, p. 563), evidenciam que "(...) a atitude do movimento operário português dos primeiros vinte anos do (...) [século $\mathrm{XX}$ ] foi evoluindo de uma forma bem consistente, partindo de uma táctica complementarista nos finais do século (...) [XIX] para uma estratégia substitucionista face ao aparelho educativo estatal português a altura". Para esse saudoso ${ }^{8}$ historiador português da educação, o movimento sindical e operário do primeiro quartel do século $\mathrm{XX}$ teria sido hegemonizado, em Portugal, pelo anarcossindicalismo. Realça, nas conclusões a que chegou em sua tese de doutoramento sobre a Escola Oficina $N^{o} 1$ de Lisboa, a importância da presença dos anarquistas e sindicalistas revolucionários portugueses no esboço de definição, em Portugal, de uma cultura de classe (operária) nos inícios do século XX. Nas palavras desse historiador:

(...) a importância de que se revestiu o factor "autónomico" presente nos escritos e nas práticas anarquistas, o qual, cruzado com o desenraizamento de populações recentemente urbanizadas que viram nas estruturas sindicais existentes formas de integração possível num meio sentido como globalmente hostil, contribuiu para o esboço de uma definição de uma "cultura de classe" que foi a base da construção de um esboço de "sociedade alternativa" ao capitalismo do princípio do século. (CANDEIAS, 1994, p. 564).

As práticas pedagógicas da Escola Oficina $\mathrm{N}^{\circ} 1$ de Lisboa, assim como as das Escolas Modernas (de Ferrer y Guardia), voltadas a uma nova forma de educar, chamaram a atenção e ganharam a admiração dos libertários que compunham o Grupo Lumen. Se deram visibilidade a tais práticas na revista Lumen, não foi com o objetivo de fazer com que elas pudessem ser tomadas como um modelo pedagógico reproduzível e capaz de substituir o modelo estatal de formação, mas, sim, para evidenciar possibilidades concretas de práticas pedagógicas voltas à formação científica (não dogmática) do ser social.

\footnotetext{
${ }^{8}$ Professor na Universidade Nova de Lisboa, falecido a 06 de novembro de 2010.
} 


\section{A Experiência da Escola Oficina N.o 1 de Lisboa}

Uma pequena matéria sobre a Escola Oficina N. ${ }^{\circ} 1$ de Lisboa foi publicada na revista Lumen, pela primeira vez, em janeiro de 1912. Foi publicada na seção "Chronica Subversiva (As Ideias e os Factos, as Pessoas e os Costumes)", então sob a responsabilidade de Braz Burity, pseudônimo de Joaquim Madureira, primeiro editor da revista.

Nessa matéria, Braz Burity apresenta a Escola Oficina como uma instituição que muito destoava do conjunto das instituições escolares portuguesas do período, por ter optado pelo ensino racional, tal como este fora proposto e praticado por Francisco Ferrer y Guardia em sua Escola Moderna, na cidade de Barcelona, nos primeiros anos do século XX. Em seguida, reproduz, textualmente, a impressão de um jornalista que, após visitar a peculiar escola, escreveu e publicou as seguintes linhas em um jornal lisboeta (não identificado por Burity):

Ao entrar naquela casa (...) sentia-se como que numa lufada de vento novo, o sadio vento da educação nova que arranca os espíritos da estagnação mental, antepondo-se na vida. Respira-se um ar de bondade, de tolerância, de simpatia que comove. Não se vê o mestre dogmático, tirano, que pede ordem e silêncio, mas o educador que procura despertar na consciência de cada um o espírito da própria individualidade, respeitando-a em si e nos outros. As crianças não sentem em torno de si nenhuma pressão, por mais leve que seja, e essa liberdade máxima é o próprio indicador de que não devem abusar. Ali não há domesticadores de crianças - há educadores que consagram toda a sua existência à obra generosa e fecunda de criar esta coisa rara - homens. (BURITY, 1912, p. 187).

Têm-se aqui alguns dos principais traços da escola desejada pelos libertários do Grupo Lumen: uma escola ativa "que arranca os espíritos da estagnação mental", que busca "despertar na consciência de cada um o espírito da própria individualidade" e que cultiva a liberdade. Em uma palavra, uma escola que "cria homens". Braz Burity finaliza a matéria chamando a atenção do leitor para três aspectos da vida da Escola Oficina, a saber:

1. ${ }^{\circ}$ - têm estado em exposição nas salas do seu edifício do largo da Graça os trabalhos escolares (alguns notáveis) executados pelos seus alunos no ano letivo agora findo; $2 .^{\circ}$ - indo até 50 alunos a sua população escolar, a direção resolveu elevar esse número a 100, a começar já neste ano letivo, sendo absolutamente gratuita, como até aqui, a frequência de 50; $3 .^{\circ}-$ o seu curso de marceneiro-entalhador (educação primária e educação profissional) foi reorganizado e além dele haverá um curso livre de pedagogia, teórico e pratico. (BURITY, 1912, p. 188). 
Dos três aspectos destacados por Burity, vale lembrar, no que se refere à gratuidade do ensino, que a Escola Oficina era mantida pela organização maçônica Sociedade Promotora de Asilos, Creches e Escolas. E, quanto à abertura de um curso livre de pedagogia, que os dirigentes da escola avaliavam ser necessário formar professores de acordo com os princípios que regiam as práticas escolares da própria instituição.

A Escola Oficina volta a ser notícia na seção "Os Livros e as Revistas", da edição de maio de 1912 (vol. I, n 11), da revista Lumen. Noticia-se, aqui, o recebimento de uma "coleção de opiniões de pedagogos, homens de ciência, literatos e estudiosos acerca da Escola Oficina”, publicada em Lisboa, em 1912, pela Sociedade Promotora de Asilos, Creches e Escolas, intitulada "Escola-Oficina n ${ }^{\circ} 1$ ". Na pequena resenha sobre a coleção, o autor refere-se à Escola Oficina como "estabelecimento de educação, único em Portugal no seu gênero", faz menção ao fato de Adolfo Lima, colaborador de Lumen, fazer parte do corpo docente da Escola, e destaca as opiniões de Rocha Martins, José de Magalhães e José de Barros sobre ela. Da opinião expressa por José de Barros, o autor da resenha destaca a seguinte passagem:

São autênticas maravilhas de compreensão pedagógica os quadros para o ensino de cosmografia, que ainda ontem revi com grande prazer, e cujo autor é o Sr. Adolfo Lima, autor também de uns quadros históricos, sistematizados, em que, de uma maneira rápida, a criança adquire uma noção segura e clara, não dos nomes dos reis e imperadores, mas da evolução coletiva da sociedade. (Lumen, vol. I, $\mathrm{n}^{\circ}$ 11, p. 292, maio 1912).

Vale destacar, da citação acima, a referência a duas das disciplinas que compunham o currículo da Escola Oficina (Cosmografia e História) e, principalmente, alguns traços da maneira como a história era ensinada nessa escola: a opção, não por uma história política voltada para os "grandes feitos" dos mandatários das nações (reis e imperadores), mas pela "evolução coletiva da sociedade". Temos, aqui, uma clara opção (de Adolfo Lima) por uma visão evolucionista ("científica") da sociedade.

Lumen também anunciava, na seção "Os Livros e as Revistas", o recebimento de relatórios do Conselho Escolar da Escola Oficina, enviados à Redação pela Sociedade Promotora de Asilos, Creches e Escolas, que, como já dito, era a proprietária e mantenedora da escola. Anunciava, ainda, o recebimento de exemplares de Educação, uma revista pedagógica, cuja feitura e edição eram de responsabilidade do corpo docente da mesma escola. Além de anunciar o recebimento de exemplares dessa revista, apresentava pequenas resenhas críticas de textos nela publicados, como o de Adolfo Lima, "Educar", e o de César Porto, “A Propósito da Educação Cívica", resenhados por Bel-Adam (Severino de Carvalho). Do primeiro texto, de autoria de Adolfo Lima, Bel-Adam destaca o seguinte trecho:

Não é pela criança, propriamente, que o professor se atormenta para conseguir o seu fim - educar; mas, sim, pelas pessoas crescidas que a todo o momento o obrigam a recomeçar, a refazer a sua obra perdida por um momento, a renovar os esforços, a uma duplicação de atividades. (LIMA apud BEL-ADAM, 1913, p. 233-234). 
Ao destacar esse trecho do texto de Lima, Bel-Adam introduz uma questão crucial para aqueles que queriam transformar, radicalmente, a sociedade, qual seja a da educação dos costumes. Educar as crianças seria tarefa relativamente fácil não fossem os adultos (pais e demais membros da comunidade em que a criança vivia) a interferirem cotidianamente no processo de formação de um ser social. Claro está que seria impossível ignorar ou abstrair tais determinações. Importa, entretanto, estar atento às estratégias acionadas por esses libertários, tendo em vista a conquista dos adultos para as causas que defendiam. Do texto de César Porto, “A Propósito da Educação Cívica”, Bel-Adam faz o seguinte comentário:

O ensino cívico deveria tentar ser desde já o ensino dos preceitos éticos, ponderados sob o aspecto do bem-estar e progresso sociais, grupados, portanto, seriados e hierarquizados por uma forma diversa daquela por que os estuda a moral; juntar-se-lhe-ia uma exposição dos direitos e deveres políticos, jurídicos, econômicos, conselhos de varia espécie e extraídos da história universal, talvez também o conhecimento de diferentes regras higiênicas, e enfim certas teorias e maneiras de entender ou sentir a existência em sociedade. Assim parece ao A., que, aliás, declara não ser isto certamente exequível de um modo definitivo e seguro no estado presente do saber. (BEL-ADAM, 1913, p. 234).

Parece haver, aqui, uma proposta radical de mudança quanto à educação cívica. Como os libertários eram contrários a toda e qualquer tentativa de doutrinação do ser social (religiosa, filosófica, política, econômica etc.), o ensino cívico, tal como começou a ser praticado sob o regime republicano, não lhes convinha. A proposta de mudanças nesse ensino, apresentada por César Porto, parece ir ao encontro dos ideais libertários do Grupo Lumen, que advogavam um ensino pautado pelo conhecimento positivo, científico. Entretanto, tanto César Porto, quanto Bel-Adam, admitiam não haver, ainda, condições propícias à execução do projeto de intervenção de César Porto, em função do estado de desenvolvimento do saber naquele momento. A ideia de progressão (evolução) do saber é, aqui, claramente explicitada.

Esses dados, extraídos da seção "Os Livros e as Revistas", são relevantes, pois evidenciam que os libertários reunidos em torno do Grupo Lumen conheciam bem a proposta pedagógica da Escola Oficina, bem como aspectos relevantes das suas práticas pedagógicas.

A propósito do conhecimento que tinham dessas práticas, vale a pena comentar uma pequena nota, de autoria de Hostilus, sobre um sarau promovido pela seção dramática de $A$ Solidária, uma associação de alunos da Escola Oficina. Hostilius compareceu ao sarau, que fazia parte das atividades festivas promovidas por aquela associação de alunos, em comemoração ao $3^{\circ}$ aniversário da Cantina Lanche-Escolar. Nesse sarau, segundo Hostilius:

houve exercícios de dicção e foram interpretadas, além do monólogo Deputado, as peças em um ato - O Senhor Alegre, de Courteline, Riqueza!, de Bourgeois e Theriet, Nguvo, o Selvagem, adaptação atualizada da comedia Arlequim, o Selvagem, de Lachevetiere, Sempre escrava?..., original sobre um dos aspectos do problema feminista, e 
Vivamos juntos!... tradução livre de Une leçon de fraternité, sobre a coeducação, de M. Vernet, com música do bailado Primavera, de Julio Cardona. (HOSTILIUS, 1913b, p. 240).

Hostilius tece dois comentários sobre o referido sarau. O primeiro deles diz respeito à utilidade dessas práticas que, segundo ele, "são como que prolongamentos das aulas", tanto pela organização dos seus programas, quanto pela aplicação a que obrigam as crianças. Além disso, nada teriam de comum "com certas festas infantis em que a cançoneta pornográfica é número obrigatório" (HOSTILIUS, 1913b, p. 240). Comentário, portanto, bastante elogioso, muito diferente do segundo, no qual foi severamente crítico. Ao comparar a referida festa com a do ano anterior, da qual também participou, afirma:

notei aqui a demasiada extensão do programa. [...] E se tanto me fosse permitido, acrescentaria que de desejar é que o programa da próxima festa seja composto apenas de peças infantis, ainda que para isso a seção tenha de fazer reprises. Pois não é verdade que os saraus teriam muito mais encanto se os pequenos intérpretes não se vissem obrigados a fingir de pessoas crescidas? (HOSTILIUS, 1913b, p. 240).

Essa nota de Hostilius foi estrategicamente publicada em um número da revista Lumen que traz a peça infantil, "Quando Formos Crescidos...”, de Adolfo Lima, antecedendo-a. Tratase de uma peça em um ato e cinco cenas, cujos personagens são Luzia (10 anos), Justiniano (12 anos) e Heliodoro (10 anos). Essa não foi a única peça da lavra de Adolfo Lima publicada na revista Lumen. Houve ainda outra, intitulada "O Auto do Luto", que integrou a edição de janeiro de 1913 da revista. Embora esta última não seja uma peça dirigida especialmente ao público infantil, foi representada no sarau de 08 de setembro de 1912, promovido pela seção dramática de $A$ Solidária. Trata-se de uma peça em um ato e três cenas, com três personagens, cada qual representando uma geração de mulheres: Maria Teófila (60 anos), Império (35 anos, filha de Maria Teófila) e Sofia (16 anos, filha de Império). Qual teria sido a opinião de Hostilius sobre a representação dessa peça pelos alunos da Escola Oficina? Não se tem registro dela.

Para encerrar a análise das menções aqui feitas à Escola Oficina na revista Lumen, uma delas, publicada na edição de fevereiro de 1913, também ela da lavra de Hostilius, foi escolhida. Trata-se de uma denúncia, ou um alerta sobre a participação (intervenção?) do Estado na vida da Escola Oficina. Nessa nota, o leitor é informado que "o Estado houve por bem estender a mão" à referia escola, "concedendo-lhe subsídio e equiparando-lhe os certificados de habilitação dos seus $2^{\circ}$ e $6^{\circ}$ graus aos certificados de exame de $1^{\circ}$ e $2^{\circ}$ graus da instrução primária oficial" (HOSTILIUS, 1913a, p. 138). Embora admita que "estender a mão" não seja o mesmo que "deitar a mão", Hostilius deixa transparecer certo temor, uma vez que essa presença do Estado poderia fazer com que diminuísse a simpatia que a escola havia angariando até então. Dessa nota de Hostilius, pode-se inferir que os subsídios que a escola (por referência à Escola Oficina, ou qualquer outra escola não-oficial) pudesse obter do Estado seriam sempre bem-vindos, desde que eles não implicassem perda de autonomia da escola. É interessante observar, entretanto, que, com esse subsídio anual do Estado, a Escola Oficina teria iniciado a educação conjunta dos dois sexos e a publicação de uma revista pedagógica, a revista Educação. Além disso, prometia para breve a abertura de um curso de Pedagogia. 


\section{A Experiência das Escolas Modernas}

A Escola Moderna, concebida e posta em prática por Francisco Ferrer y Guardia, considerado o apóstolo da instrução ${ }^{9}$, foi notícia e objeto de análise e discussão em vários números da revista Lumen. Noticia-se, por exemplo, o recebimento de revistas, boletins e jornais das mais diferentes partes do mundo, boa parte deles com uma proposta editorial de divulgação da experiência de Ferrer y Guardia na sua Escola Moderna, em Barcelona. Dentre os impressos que chegaram à Redação de Lumen, destacamos os seguintes: 1) Francisco Ferrer, revista de educação racional, de Buenos Aires, continuadora da obra da Escola Moderna, dirigida por Samuel Torner; 2) Infancia, revista mensal de educação racional, de Montevidéu; 3) Boletim da Escola Moderna Francisco Ferrer, de Milão, dirigido por Luigi Molinari; 4) um número ilustrado do jornal A Aurora, publicado na cidade do Porto, comemorativo do dia 13 de outubro de 1909, data do fuzilamento de Ferrer. Também se noticia a chegada à Redação de livros sobre Francisco Ferrer, ou sobre a sua Escola Moderna, com a promessa de que eles seriam oportunamente resenhados, como o livro de Luigi Molinari, Vita e Opera di Francisco Ferrer, publicado em Milão (sem indicação do ano da publicação). Publicam-se, por fim, resenhas de textos (artigos de revistas e livros), chegados à Redação, sobre práticas de educação racional em diferentes países, tais como: 1) o artigo de Jean Wintsch, "L’École Ferrer de Lausanne", publicado na revista Les Temps Nouveaux, de Paris, em 24 de junho de 1911;2) o artigo de Samuel Torner, "La enseñanza racionalista", publicado na revista Francisco Ferrer, de Buenos Aires, 15 de setembro de 1911.

Dos artigos sobre educação racional, chegados à Redação de Lumen e que foram por ela resenhados e publicados, gostaríamos de aqui comparar e comentar o que se pôde extrair das duas resenhas acima citadas. A primeira delas, que versa sobre o artigo de Jean Wintsch, "L'École Ferrer de Lausanne", traz algumas informações sobre a escola de Lausanne e uma sequência de excertos do referido artigo. Cada excerto traz informações importantes sobre os objetivos visados por essa escola, quais eram os seus métodos de ensino e o que a distinguia das demais escolas suíças, fossem elas oficiais ou "novas" ("novas", por observarem os princípios da pedagogia moderna, da escola ativa).

Os objetivos visados pela Escola Ferrer, em Lausanne, eram: "fazer praticar às crianças, a aprendizagem da vida, e não a da docilidade"; "preparar futuros produtores que saibam servirse das mãos, dos olhos e da inteligência"; fazer com que os filhos se tornassem "seres fortes, melhores e mais livres" do que os pais (Lumen, vol. I, no 4, p. 109, set. 1911). Esses objetivos, entretanto, deveriam ser perseguidos sem violência ou coação. $\mathrm{O}$ seu método de ensino valorizava: a "leitura ensinada por jogos de letras"; a escrita, por "jogos de substantivos (Cempuis)"; "a aritmética, pelos exercícios práticos (...), pelas medições nas estradas, nos terrenos"; para o ensino da história, "coleções de estampas feitas pelas crianças, (...) máquina de projeções com numerosas vistas sobre as transformações da vida, visitas aos museus"; muito desenho, pois este é visto como "uma arte de observação por excelência, ao mesmo tempo [em] que desenvolve a habilidade da mão" (Lumen, vol. I, no 4, p. 109, set. 1911). A quantidade de

\footnotetext{
${ }^{9}$ Alcunha atribuída a Francisco Ferrer y Guardia por Hostilius, um dos responsáveis pela seção “As Ideias e os Fatos, as Pessoas e os Costumes” (Cf. HOSTILIUS, “A Propósito de Ferrer”, Lumen, vol. II, n 14, p. 39-40, nov. 1912).
} 
lições que se davam fora da aula era o que distinguia nitidamente a Escola Ferrer das demais escolas suíças, segundo Jean Wintsch. Subjacente a essa prática, o suposto de que "não é entre quatro paredes que se pode aprender a conhecer a vida", mas nos lugares onde ela se manifesta: nos campos, nas matas, nos estábulos, nas capoeiras. Nesses lugares, as crianças poderiam encontrar operários, camponeses que lhes diriam "mais e melhor que os doutos manuais". (Lumen, vol. I, $n^{\circ}$ 4, p. 110, set. 1911). A educação e instrução da criança eram, porém, apenas uma parte do conjunto de ações da Escola Ferrer, de Lausanne. Sobre essas outras ações, diznos o autor do artigo:

À noite organizamos cursos para operários, cursos práticos naturalmente, dirigidos por técnicos de ofício; é assim que atualmente já funciona um curso de desenho para pedreiros, dirigido por um arquiteto; daqui a alguns meses abriremos cursos de elocução, de história dos trabalhadores, de higiene profissional e popular, de pedagogia para pais. Será uma grande tarefa a realizar, mas que dirigida e organizada pelos diretos interessados, pelos trabalhadores, já se não perderá na ciência livresca e metafísica das antigas universidades populares tão miseravelmente fracassadas. (Lumen, vol. I, $\mathrm{n}^{\circ} 4$, p. 110, set. 1911).

A segunda resenha sobre educação racional publicada na revista Lumen tem por objeto o artigo de Samuel Torner, "La enseñanza racionalista", publicado na revista Francisco Ferrer, editada em Buenos Aires (Lumen, vol. I, nº 6, p. 158, nov. 1911). Torner foi diretor de uma Escola Moderna, mas nenhuma informação é dada ao leitor sobre a localização dessa escola (supõe-se que em Buenos Aires), como ela funcionou e por quanto tempo existiu. À semelhança dos procedimentos adotados na resenha anterior, também nesta o resenhista traz algumas informações iniciais sobre o texto em questão (um artigo), transcrevendo, na sequência, alguns trechos do mesmo. Diferentemente do que fez o autor do texto resenhado anteriormente, neste, Torner não discorre sobre uma experiência concreta de ensino, propriamente dita, mas teoriza sobre práticas de escolas racionalistas, talvez embasado em sua própria experiência, posto ele ter sido diretor de uma Escola Moderna. Segundo o resenhista, Torner, em seu artigo, defende a tese de que a escola "não pode ser anarquista, pois tendo como base a investigação e comprovação científica, não pode ter, como não o tem a ciência, um programa cerrado" (Lumen, vol. I, nº 6, p. 158, nov. 1911). Ela deve ser neutra, pois "não pertence a nenhum partido, religião ou ideia determinada". Neutra e praticante de um ensino racional e científico, "que principie respeitando a individualidade da criança e acabe por fazê-la conhecedora de todos os problemas como a vida exige" (Lumen, vol. I, nº 6, p. 158, nov. 1911). Ao indagar de que modo esse objetivo poderia ser alcançado, o próprio Torner responde:

Ensinando à criança dia a dia todos os fenômenos físicos do universo, dando-lhe noção clara, terminante, sem preconceitos, da força e matéria, para que saiba que só é verdadeiro o que pode demonstrar-se, levando esta instrução cientifica a que não conceba nenhum mistério de criação, nem de divindade. E com isto, a explicar-lhe os fenômenos sociais, as injustiças, tendo, porém, a especial reserva de fazer-lhe 
conhecer só o provado, e estes conhecimentos ministrá-los devidamente, gradualmente, tendo em conta a idade da criança para que possa compreender e assimilar cada nova impressão. Sem falar-lhe de ideias, de religião, de partidos, obteremos da criança um indivíduo judicioso, razoável, que aceitará todo o progresso e, sobretudo, conservará integralmente a sua personalidade. (Lumen, vol. I, $\mathrm{n}^{\mathrm{o}}$ 6, p. 158, nov. 1911).

Esses procedimentos, como se pode observar, são muito distintos daqueles adotados na Escola Ferrer, de Lausanne. A proposta de Torner parece corroborar as principais características de um ensino pautado pelo verbalismo do professor e pela passividade do aluno. Um ensino que não considera (mas que talvez não despreze) o interesse e o papel ativo da criança no seu processo de formação. Segundo Ferrer, "o valor da educação reside no respeito da vontade física, intelectual e moral da criança"; isenta de todo dogmatismo, a verdadeira educação "deixa à própria criança a direção do seu esforço e que apenas se propõe secundá-lo na sua manifestação". (FERRER, 1912, p. 25). Mas o próprio Ferrer admite ser muito fácil desrespeitar esse princípio. Segundo ele, o educador é aquele que "impõe, obriga [e] violenta sempre". Mas o "verdadeiro" educador, "contra as suas próprias ideias e vontades, pode defender a criança, apelando o mais possível para as próprias energias da mesma criança". (FERRER, 1912, p. 25).

Além desses dois relatos sobre educação racional, os leitores de Lumen também puderam ter acesso a um interessante texto de autoria de Ferrer y Guardia, intitulado "A Renovação da Escola", publicado três anos após a sua morte (Lumen, vol. I, n 14, p. 25-27, nov. 1912). Fonte de inspiração de práticas educacionais libertárias em diversos países do mundo, como se viu, cabe aqui destacar algumas das considerações feitas por Ferrer sobre o assunto, especialmente no que toca à sua experiência junto à Escola Moderna, em Barcelona, tendo por base o que a revista Lumen fez circular.

Ferrer não afirma de forma categórica, nesse seu texto, quais características a educação do futuro deveria ter, por uma razão muito simples: para ele, essa educação seria uma realização dos homens do futuro. O que, entretanto, os homens do presente poderiam ou deveriam fazer, segundo ele, tendo em vista a formação desse homem do futuro, que seria o principal responsável pela tão desejada educação do futuro? Ao passar em revista as práticas dos então controladores da organização escolar, pergunta se esses sujeitos aspiravam a suprimir a violência das escolas. Para ele, não aspiravam. Ao contrário, empregavam todos os meios eficazes disponíveis, novos ou não, para a formação de seres que aceitassem todos os convencionalismos, todas as preocupações, todas as mentiras, sobre as quais a sociedade se fundava (FERRER, 1912, p. 26). Que homens uma escola renovada que se apresentasse como alternativa à escola do presente poderia formar?

homens capazes de evolucionar incessantemente, capazes de destruir, de renovar constantemente os meios e de renovarem-se eles próprios; homens, cuja independência intelectual seja a força suprema, que jamais se sujeitem a coisa alguma, dispostos sempre a aceitar o melhor, ditosos pelo triunfo iniludível das ideias novas e que aspirem a viver vidas múltiplas numa só vida. (FERRER, 1912, p. 26). 
Mas a sociedade, segundo Ferrer, temia tais homens e dela não se podia esperar o aval para uma educação capaz de produzi-los. O que, então, poderia ser feito? Como alcançar o objetivo de formar indivíduos intelectualmente livres e independentes?

Pondo diretamente mãos à obra, favorecendo a fundação de escolas novas, onde quanto possível se estabeleça esse espírito de liberdade que, ao que pressentimos, há de dominar toda a obra da educação do futuro. (...) Podemos destruir tudo quanto na escola atual corresponde à organização da violência, os meios artificiais por que as crianças se encontram alheadas da natureza e da vida, a disciplina intelectual e moral de que se servem para impor-lhes pensamentos feitos, crenças que depravam e aniquilam as vontades. Sem receio de nos enganarmos, podemos por a criança no meio que a solicita, o meio natural onde se achará em contacto com tudo o que a ama e onde as impressões vitais substituirão as fastidiosas lições de palavras. Se não fizéssemos mais do que isto, teríamos preparado em grande parte a emancipação da criança. Em tais meios poderíamos aplicar livremente os dados da ciência e trabalhar com êxito. (FERRER, 1912, p. 26-27).

Com a clareza, entretanto, de que nem sempre poderiam realizar todos os seus sonhos, sobretudo por falta de saber, dado o então ritmo de desenvolvimento da ciência, sobretudo no que dizia respeito ao conhecimento da criança. Por ignorância, poderiam até empregar meios reprováveis. Mesmo assim, estariam fazendo "mais e melhor, apesar da imperfeição da (...) obra", do que realizava a escola de então. Prefeririam "a espontaneidade livre de uma criança que nada sabe, à instrução de palavras e à deformação intelectual de uma criança" que sofria a educação que se lhe ministrava nas escolas doutrinárias, oficiais ou não. (FERRER, 1912, p. 27). Não deveriam, portanto, esperar o término dos estudos científicos sobre a criança para empreenderem a renovação da escola. Na escola renovada (racional), deveriam aplicar o que sabiam e o que sucessivamente fossem aprendendo, para que as crianças pudessem se desenvolver, "livres e felizes, segundo as suas aspirações". (FERRER, 1912, p. 27).

É sobre esse projeto de escola renovada (racional) que Ferrer discorre no artigo que a revista Lumen fez circular em Portugal. Projeto que ele concebeu, pôs em prática na cidade de Barcelona e pelo qual batalhou até o dia em que foi fuzilado pelas forças conservadoras de Espanha, em 13 de outubro de 1909.

\section{Educar ou Instruir? A Posição do Grupo Lumen}

Em meio a uma insatisfação generalizada quanto ao ensino religioso, um número cada vez maior de intelectuais portugueses começou a preconizar e a praticar, no início do século $\mathrm{XX}$, outras modalidades de ensino. $\mathrm{O}$ ensino laico foi uma das primeiras, senão a primeira modalidade a fazer oposição à forma religiosa de ensinar. Mas quando se percebeu "que nas escolas laicas não se fazia outra coisa que pôr o civismo no lugar da religião, o Estado no lugar de Deus, surgiu a idéia de um ensino alheio às doutrinas tanto religiosas como políticas" 
(Lumen, vol. II, $\mathrm{n}^{\mathrm{o}}$ 15, p. 57, dez. 1912). Foi nesse contexto que as escolas, neutral e racionalista, foram apresentadas como práticas alternativas ao modelo laico. Posteriormente, outras modalidades de ensino far-se-iam conhecidas, como a naturalista e a realista, por exemplo.

Os anarquistas e sindicalistas revolucionários portugueses, reunidos em torno do Grupo Lumen, defendiam a tese segundo a qual, independentemente do nome que se atribuísse a uma escola e ao ensino nela praticado (laico, neutral, racionalista, naturalista, ou realista), essa escola deveria instruir, mas jamais educar. Tais dirigentes, e organizadores da cultura, consideravam "defeituosos" todos os métodos de ensino que não distinguissem perfeitamente ensino e educação. Diziam, eles:

Se reduzíssemos a questão ao ensino propriamente dito, não haveria problema. Há-o, porque o que se quer em todo o caso é educar, inculcar às crianças um modo especial de se conduzirem, de serem e de pensarem. E contra esta tendência, (...) imposição, erguer-se-ão sempre quantos ponham acima de qualquer finalidade, a independência intelectual e corporal da juventude. (Lumen, vol. II, $\mathrm{n}^{\circ}$ 15, p. 57, dez. 1912).

A seção "Pela Instrução", da revista Lumen, explicita bem a distinção entre instrução e educação, acima referida. Com o subtítulo "O que se ensina - Como se ensina", os diretores da revista denunciavam práticas escolares que consideravam doutrinárias. A seguir, transcrevemos, a título de ilustração, duas dessas denúncias:

Em plena instrução laica: No Liceu de Camões, um aluno é chamado e acidentalmente o professor pergunta-lhe se sabe o Padre-nosso. Como a resposta seja [sic] negativa, o professor, colérico, manda o aluno para o lugar, enchendo-o dos epítetos de selvagem e mau, pois "quem não sabe o padre-nosso ha de ser mau por força" "nunca poderá ser bom"! (Lumen, vol. I, nº 2, p. 58, jul. 1911).

Em um dos liceus de Lisboa - aula de história ( $2^{\circ}$ ano), o professor, dirigindo-se a um dos alunos, inquire:

- Que sucedeu aos deuses da Assíria?

Silêncio do rapaz.

- Morreram. E que sucedeu aos deuses da Grécia?

$\mathrm{O}$ mesmo silêncio.

- Morreram também. E não se lhes aproveitou nem a mais pequenina parte.

É isto assim, quando não é o professor de inglês a fazer propaganda da religião, do despotismo e das altas qualidades militares de qualquer grãocapitão ou o professor de português a aplaudir a atual guerra ítalo-turca, por servir a causa da civilização. (Lumen, vol. I, nº 8, p. 200, jan. 1912). 
Para os intelectuais dirigentes do Grupo Lumen, a "verdadeira instrução", independentemente do nome que a ela se desse, deveria assentar-se exclusivamente nas "verdades cientificamente adquiridas" e ser totalmente alheia aos dogmas religiosos, à opinião política, aos ideais sociais, econômicos e filosóficos. Para poder ensinar, as doutrinas não fariam nenhuma falta ao professor, fossem elas laicas, racionalistas, naturalistas ou realistas. Por essa razão, "a escola não poderia ser nem republicana, nem maçônica, nem socialista, nem anarquista, nem muito menos religiosa." (Lumen, vol. II, $\mathrm{n}^{\circ} 15$, p. 58-59, dez. 1912). O que deveria ser, então, a escola?

A escola não pode nem deve ser mais do que o ginásio adequado ao total desabrochar, ao completo desenvolvimento dos indivíduos. Não há, pois, que dar à juventude ideias feitas, quaisquer que sejam, porque isso implica castração e atrofia daquelas mesmas faculdades que se pretende excitar.

Há que instituir o ensino fora de todo o espírito de facção, arrancando a juventude do poder dos doutrinários embora se digam revolucionários. Verdades conquistadas, universalmente reconhecidas, bastarão para formar indivíduos livres intelectualmente. ((Lumen, vol. II, $\mathrm{n}^{\circ} 15$, p. 58-59, dez. 1912).

Eram, portanto, intelectuais contrários a todo e qualquer espírito de facção e práticas doutrinárias e favoráveis a um modelo de ensino pautado pelo conhecimento científico e comprometido com a formação de indivíduos intelectualmente livres.

Tal posicionamento não pressupunha, entretanto, a negação de um ensino mais abrangente, que pusesse o educando, sobretudo o jovem educando, em contato com "o desenvolvimento de todas as teologias, de todos os sistemas filosóficos, de todas as formas de organização passadas, presentes e futuras, de todos os fatos e de todas as idealidades". (Lumen, vol. II, no 15 , p. 59, dez. 1912). Mas esse complemento escolar necessário à formação do indivíduo intelectualmente livre não poderia prescindir do ensino das verdades científicas comprovadas que à escola caberia ensinar.

Os dirigentes do Grupo Lumen não esclarecem quais instituições sociais deveriam se responsabilizar por esse ensino complementar. Porém, em um e outro artigo sobre instrução publicado na revista Lumen percebe-se que a própria instituição escolar poderia, segundo eles, desempenhar esse papel. Mas advertem:

São coisas distintas, explicar ideias religiosas e ensinar um dogma religioso; expor ideias políticas e ensinar democracia, socialismo e anarquia. É necessário explicar tudo, porém não impor coisa alguma por certa e justa que se creia. Só por este preço a independência intelectual será efetiva. (Lumen, vol. II, nº 15, p. 59-60, dez. 1912).

Caberia ao preceptor, ou professor, ser neutro. Caberia a ele ensinar, mas não dogmatizar, doutrinar. Contrários a toda e qualquer prática doutrinária, advogavam caber a cada indivíduo, ante os ensinamentos adquiridos dentro e fora da escola, formar-se a si mesmo. 
A escola que os anarquistas e sindicalistas revolucionários portugueses do Grupo Lumen queriam e defendiam não se prendia, portanto, a uma denominação ou método de ensino específico (neutral, racionalista, naturalista ou realista). Seria toda e qualquer escola na qual melhor e mais se suscitasse nos jovens "o desejo de saberem por si mesmos, de formarem suas próprias ideias”. (Lumen, vol. II, n 15, p. 60, dez. 1912).

\section{Considerações Finais}

Em um de seus textos sobre escolas operárias portuguesas, Candeias (1987) destaca que, muito anos antes de as teses de Louis Althusser sobre as relações Educação-Sociedade terem sido formuladas e divulgadas, a realidade abarcada por elas já se fazia sentir no movimento operário português do primeiro quartel do século XX, então fortemente marcado pela filosofia anarcossindicalista. As máximas de tal filosofia, no que respeita à educação, eram:

educar sim, mas segundo os objetivos políticos, sociais e culturais que visem a formação de um homem livre, racional e integral. Livre dos dogmas da religião e do Estado; racional ao ter como critério a verdade provada pela ciência; integral aproveitando e explorando de uma forma global as potencialidades intelectuais e afectivas do ser humano; integral ainda ao propor a educação politécnica, que recuse a divisão do trabalho manual - trabalho intelectual, que para os anarquistas será uma das causas e um dos resultados da divisão da sociedade em classes. (CANDEIAS, 1987, p. 328).

Os integrantes do Grupo Editor Lumen declaravam-se "revolucionários" e ao mesmo tempo "evolucionistas", o que, segundo eles, seria "mais científico". Por isso, defenderam, nas páginas da revista Lumen, uma escola que primasse pelo ensino científico (desinteressado) e fosse avessa às manifestações doutrinárias (religiosas, filosóficas, políticas e econômicas). Defendiam uma escola, cujo único objetivo fosse o de formar indivíduos intelectualmente livres. Seu projeto de intervenção na realidade social, entretanto, não se limitava a essas medidas.

Por acreditarem na evolução da ciência, os dirigentes da revista Lumen vislumbravam, para um futuro próximo, a existência de uma sociedade livre de todas as instituições sociais cerceadoras da plenitude do ser, criadas e reformuladas, pelas diferentes formas de organização social praticadas pela humanidade ao longo da sua história. A construção dessa sociedade (ácrata) dependeria da existência de sujeitos intelectualmente livres, livres de todas as amarras doutrinárias. Compreende-se, assim, o sentido que os integrantes do Grupo Lumen atribuíam à escola em uma sociedade que ainda não era aquela que eles desejavam e pela qual tanto lutavam. 


\section{Referências}

ACCIÓN LIBERTÁRIA. O Problema do Ensino. Lumen, Lisboa, vol. II, no 15, p. 57-60, dez. 1912.

BARREIRA, L. C. A Educação Libertária no Boletim Cultura Popular (Lisboa, 1919). Perspectiva - Revista do Centro de Ciências da Educação, Florianópolis, SC, vol. 29, nº 1, p. 339-363.

BEL-ADAM [Severino de Carvalho]. Os Livros e as Revistas. Lumen, Lisboa, vol. II, $\mathrm{n}^{\circ}$ 21, p. 232-235, jun. 1913.

BURITY, B. [Joaquim Madureira]. A Escola Oficina $N^{\circ} 1$ de Lisboa. Lumen, Lisboa, vol. I, no 8 , p. 187-188, jan. 1912.

CANDEIAS, A. As Escolas Operárias Portuguesas do Primeiro Quarto do Século XX. Análise Psicológica, Lisboa, nº 3, série V, p. 327-362, jul. 1987.

CANDEIAS, A. Educar de outra Forma: a Escola Oficina $\mathbf{N}^{\circ} 1$ de Lisboa, 1905-1930. Lisboa: Instituto de Inovação Educacional, 1994.

CRUZ, H. F.; PEIXOTO, M. R. C. Na Oficina do Historiador: conversas sobre história e imprensa. Projeto História, São Paulo, no 25, p. 255-272, dez. 2007.

DARNTON, R. Introdução. In: DARNTON, R.; ROCHE, D. (orgs.). Revolução Impressa: A Imprensa na França, 1775-1800. São Paulo: Editora da Universidade de São Paulo, 1996, p. 15-17.

ESCOLANO BENITO, A. Las Culturas de la Escuela en España. Tres Cortes Historiográficos. Pro-Posições, Campinas, SP, vol. 16, nº 1 (46), p. 41-63, jan./abr. 2005.

FERRER, F. A Renovação da Escola. Lumen, Lisboa, vol. I, nº 14, p. 25-27, nov. 1912.

HOSTILIUS. Escola Oficina No 1. Lumen, Lisboa, vol. II, nº 17, p. 138, fev. 1913 a.

HOSTILIUS. Escola Oficina No 1. Lumen, Lisboa, vol. II, no 22, p. 240, jul. 1913b.

LIMA, A. Educação Integral. Lumen, Lisboa, vol. I, nº 5, p.116-122, out. 1911.

LUMEN. A Vida e o Ideal. Lisboa: Grupo Editor Lumen, maio 1911/set. 1913. 